\title{
Prevalence of electrocardiographic abnormalities in West-Asian and African male athletes
}

\author{
M G Wilson, 1 J C Chatard, ${ }^{1}$ F Carre, ${ }^{2}$ B Hamilton, ${ }^{1}$ G P Whyte, ${ }^{3}$ S Sharma, ${ }^{4}$ H Chalabi ${ }^{1}$
}

${ }^{1}$ ASPETAR, Oatar Orthopaedic and Sports Medicine Hospital, Doha, Qatar

${ }^{2}$ Rennes 1 University, Pontchaillou Hospital, INSERM

U 642, Rennes, France ${ }^{3}$ Research Institute for Sport and Exercise Science, Liverpool John Moores University, Liverpool, UK ${ }^{4}$ Department of Heart Muscle Disorders and Sports Cardiology, St George's Hospital, London, UK

\section{Correspondence to}

Mathew Wilson, ASPETAR, Oatar Orthopaedic and Sports Medicine Hospital,

P0 Box 29222, Doha, Oatar; mathew.wilson@aspetar.com

Accepted 14 April 2011 Published Online First 19 May 2011

\section{ABSTRACT \\ Objectives To evaluate the electrocardiographic (ECG)} characteristics of West-Asian, black and Caucasian male athletes competing in Oatar using the 2010 recommendations for 12-lead ECG interpretation by the European Society of Cardiology (ESC).

Design Cardiovascular screening with resting 12-lead ECG analysis of 1220 national level athletes

(800 West-Asian, 300 black and 120 Caucasian) and

135 West-Asian controls was performed.

Results Ten per cent of athletes presented with 'uncommon' ECG findings. Black African descent was an independent predictor of 'uncommon' ECG changes when compared with West-Asian and Caucasian athletes $(p<0.001)$. Black athletes also demonstrated a significantly greater prevalence of lateral T-wave inversions than both West-Asian and Caucasian athletes (6.1\% vs $1.6 \%$ and $0 \%, p<0.05)$. The rate of 'uncommon' ECG changes between West-Asian and Caucasian athletes was comparable (7.9\% vs $5.8 \%, p>0.05)$. Seven athletes $(0.6 \%)$ were identified with a disease associated with sudden death; this prevalence was two times higher in black athletes than in West-Asian athletes (1\% vs $0.5 \%)$, and no cases were reported in Caucasian athletes and West-Asian controls. Eighteen West-Asian and black athletes were identified with repolarisation abnormalities suggestive of a cardiomyopathy, but ultimately, none were diagnosed with a cardiac disease.

Conclusion West-Asian and Caucasian athletes demonstrate comparable rates of ECG findings. Black African ethnicity is positively associated with increased frequencies of 'uncommon' ECG traits. Future work should examine the genetic mechanisms behind ECG and myocardial adaptations in athletes of diverse ethnicity, aiding in the clinical differentiation between physiological remodelling and potential cardiomyopathy or ion channel disorders.

\section{BACKGROUND}

Electrocardiographic (ECG) alterations are common in athletes and usually reflect a physiologically benign remodelling of the heart as a response to regular intensive exercise, so called athletes heart. ${ }^{1}$ However, some features observed in athlete's ECG may represent an underlying inherited or congenital cardiovascular abnormality, potentially propagating sudden cardiac death (SCD). ${ }^{2}$ Preparticipation screening utilising a 12-lead ECG may identify pre-existing cardiovascular abnormalities. ${ }^{3}$ Recent data, however, suggest that an athlete's ethnic origin may have a significant impact on both their cardiovascular response to exercise and risk of SCD. ${ }^{4-7}$ Qatar is an Emirate in the Gulf States of West Asia, whose athletes are heterogeneous in ethnic origin. There is no data on ECG alterations found in West-Asian athletes, potentially increasing the risk of generating false-positive diagnoses and unnecessary disqualification. The present study aimed to evaluate the ECG characteristics of West-Asian, black and Caucasian male athletes competing in Qatar using the 2010 recommendations for 12-lead ECG interpretation by the 2010 European Society of Cardiology (ESC). ${ }^{8}$

\section{METHODS}

Ethical approval was obtained from the Qatar Orthopaedic and Sports Medicine Hospital ethics committee, with all athletes providing informed consent.

\section{Subjects}

Eight hundred West-Asian male athletes and 135 sedentary West-Asian male controls were recruited from 7 Gulf States (Qatar, Bahrain, Oman, UAE, Kuwait, Yemen and Saudi-Arabia) and 6 MiddleEastern countries (Egypt, Jordan, Palestine, Syria, Iraq and Lebanon). Three hundred black athletes from 7 African countries (Sudan, Somalia, Ghana, Nigeria, Senegal, Cameroon and Ethiopia) were also recruited, along with 120 Caucasian athletes from the USA, Canada and Australia. All athletes competed at the national level and exercised $\geq 6$ $\mathrm{h} /$ week. West-Asian controls performed physical activity for less than $2 \mathrm{~h}$ /week. The term 'WestAsian' denoted individuals of Gulf or MiddleEastern descent and 'black' denoted individuals of African descent.

Physical examination was based on the ESC Sport's Cardiology Section Consensus statement, ${ }^{9}$ whereas the medical history addressed present and past complaints as well as family history (FH). Athletes completed the questionnaire with the help of nurses who were fluent in Arabic, French or English. Measurement of height, body mass, brachial artery blood pressure in the supine position, precordial auscultation in supine and standing positions and assessment for any physical characteristic of Marfan's syndrome were undertaken by a sports medicine physician.

\section{Resting 12-lead ECG}

A standard 12-lead ECG was obtained using a COSMED Quark (Rome, Italy). All ECGs were reported independently by two experienced investigators, with third opinions sought from two international cardiologists. Athletes' ECG characteristics were classified into 'common' and online under the BMJ Journals unlocked scheme, see http:// bjsm.bmj.com/info/unlocked.dtl 
'uncommon' traits (table 1) according to the recent 2010 ESC report. ${ }^{8}$ The PR interval, ORS duration, OT interval, ORS axis, $\mathrm{Q}, \mathrm{R}, \mathrm{S}$ and $\mathrm{T}$ wave voltage and ST segments were measured in each lead. P wave voltage was measured in lead V1 alone. Right atrial enlargement was defined as a $\mathrm{P}$ wave voltage $\geq 0.25 \mathrm{mV}$. Left atrial enlargement was defined as a biphasic P wave in V1 where the terminal portion was more negative than $-0.1 \mathrm{mV}$ and $\geq 0.04 \mathrm{~s}$ in duration. Despite not being listed in the 2010 ESC report, both left 'and right' atrial enlargement(s) were considered 'uncommon' findings. Left axis deviation was defined as a QRS axis more negative than $-30^{\circ}$ and right axis deviation as a QRS axis more positive than $+120^{\circ}$. Left bundle branch block was defined as QRS duration $\geq 0.12 \mathrm{~s}$, whereas an RSR pattern in anterior precordial leads of $\geq 0.12 \mathrm{~s}$ was consistent with complete right bundle branch block (RBBB) or RSR pattern in $\mathrm{V} 1<0.12 \mathrm{~s}$ consistent with incomplete RBBB. A PR interval $\geq 0.20$ s following exercise or hyperventilation was considered as first-degree arterioventricular (AV) block. The QT intervals were corrected for heart rate (HR) (OT $)$ using Bazett's formula. A OT interval was considered abnormally prolonged if $\geq 470 \mathrm{~ms} .{ }^{10}$ Left ventricular hypertrophy (LVH) was calculated in two ways: (1) Sokolow-Lyon voltage (sum of amplitude of the $\mathrm{S}$ wave in lead $\mathrm{V} 1$ and the $\mathrm{R}$ wave in lead V5 or V6 $\geq 3.5 \mathrm{mV}$ ) and (2) Romhilt-Estes LVH probable score $\geq 4$. Right ventricular hypertrophy was defined by the sum of the $\mathrm{R}$ in $\mathrm{V} 1$ and the $\mathrm{S}$ in $\mathrm{V} 6$ exceeding $1.05 \mathrm{mV}$. A Q wave was considered abnormal if it exceeded $0.04 \mathrm{~s}$ in duration and/or if the depth of the $\mathrm{Q}$ wave exceeded $25 \%$ of the height of the $\mathrm{R}$ wave. T-wave inversions or ST segment depression $(\geq 2 \mathrm{~mm})$ in $\geq 2$ contiguous leads were considered significant, other than in leads V1, aVR and III. Early repolarisation pattern was defined as an elevation of the ORS-ST (J-point) $\geq 0.1 \mathrm{mV}$ from baseline in at least two peripheral or precordial leads. Furthermore, despite being mentioned as a potential early repolarisation modification, ${ }^{8}$ the pattern of J-point upward/domed convexity ST elevation followed by inverted T waves (V1-V4) was classified as an 'uncommon' ECG finding until proven otherwise.

\section{Further evaluation}

Athletes presenting with cardiac symptoms, abnormal physical examinations, an FH of SCD and/or uncommon ECG findings (table 1) were investigated further with a variety of methods, including standard and tissue Doppler echocardiography, 24-h Holter ECG, maximal exercise stress testing, cardiac magnetic resonance (CMR) imaging and genetic mutation analysis to establish a diagnosis. In athletes with persisting diagnostic uncertainty, first-degree relatives were invited for

Table 1 Classification of abnormalities of the athlete's ECG ${ }^{8}$

\begin{tabular}{ll}
\hline $\begin{array}{l}\text { Common and training-related } \\
\text { ECG changes }\end{array}$ & $\begin{array}{l}\text { Uncommon and training-unrelated } \\
\text { ECG changes }\end{array}$ \\
\hline Sinus bradycardia & T-wave inversion \\
First-degree AV block & ST segment depression \\
Incomplete right bundle branch block & Pathological 0 waves \\
Early repolarisation & Left atrial enlargement \\
Isolated QRS voltage criteria for & Left axis deviation/left anterior \\
left ventricular hypertrophy & hemiblock \\
& Right axis deviation/left posterior \\
& hemiblock \\
& Right ventricular hypertrophy \\
& Ventricular pre-excitation \\
& Complete left or right bundle branch \\
& blockLong/short-0T interval \\
& Brugada-like early repolarisation \\
\hline
\end{tabular}

cardiovascular screening or attempts were made to persuade the athlete to detrain for 1-3 months followed by repeat evaluation. ${ }^{11}$

\section{Statistical analysis}

All data were coded and analysed using PASW version 18.0. An ANOVA was used to compare athlete demographics and ECG characteristics between ethnic groups. Statistical relations of common and uncommon ECG abnormalities were compared with ethnicity, age, body surface area (BSA) and sports. Statistical significance was established by means of $\chi^{2}$ test or by Fischer's exact test when expected cell frequencies were less than 5. OR and 95\% CIs were determined using univariate and multivariate analyses. A p value $<0.05$ was considered significant.

\section{RESULTS}

\section{Racial and sporting demographics}

Athletes (aged $22.6 \pm 6$ years; range $12-35$ years) were engaged in 17 sporting disciplines. Qatar's most popular sports are football (61\%), basketball (7\%), volleyball (5\%) and handball (5\%). West-Asian athletes were significantly younger, but showed no differences in height, body mass or BSA compared with West-Asian controls. In contrast, black athletes and Caucasian athletes were significantly older $(p<0.001)$, heavier $(p<0.001)$, taller $(p<0.001)$ and had a larger BSA $(p<0.001)$ than WestAsian athletes (table 2).

\section{Health questionnaire and physical examination}

Two hundred and sixteen athletes (18\%) reported at least one positive finding in the $\mathrm{FH}$ questionnaire. One hundred and twenty-one athletes (10\%) reported an $\mathrm{FH}$ of hypertension, whereas $65(5.3 \%)$ reported an $\mathrm{FH}$ of cardiovascular disease. Seventeen West-Asian (2.1\%) and 14 black (4.7\%) athletes reported an FH of SCD concerning a young first-degree family relative. Three West-Asian and one black athlete reported an FH of Marfan's syndrome. There was no self-reported history of hypertrophic cardiomyopathy (HCM), dilated cardiomyopathy, valvular diseases and/or aneurysms in any athlete. Only eight athletes reported cardiovascular symptoms either at rest or during physical activity. All Caucasian athletes were asymptomatic and did not report an FH of SCD or Marfan's syndrome. Forty-six (3.8\%) athletes presented with heart murmurs during physical examination, including 26 WestAsian (3.3\%) and 20 black athletes (6.7\%). Overall, 270 athletes $(22 \%)$ had at least one finding on history and physical examination that warranted further discussion for possible secondary cardiovascular evaluation.

\section{ECG findings}

Using the 2010 ESC position statement on ECG interpretation (table 1), $91.7 \%$ of all athletes demonstrated 'common' ECG changes. A further $9.9 \%$ presented with 'uncommon' ECG changes (table 3). West-Asian athletes demonstrated a significantly greater rate of uncommon ECG changes than WestAsian controls $(7.9 \%$ vs $0 \%, \mathrm{p}<0.05)$; however, there were no significant differences between West-Asian and Caucasian athletes $(7.9 \%$ vs $5.8 \%$, p $>0.05)$. Black athletes demonstrated a significantly greater rate of uncommon ECG changes than both West-Asian and Caucasian athletes $(18 \%$ vs $7.9 \%$ and $5.8 \%$; $\mathrm{p}<0.001$, respectively). Accordingly, athletes of black African descent were significantly more likely to have uncommon 
ECG changes than West-Asian and Caucasian athletes ((OR) $2.56,95 \%$ (CI) 1.73 to $3.8, p<0.001$ and $3.50,95 \%$ (CI) 1.56 to $8.02, \mathrm{p}<0.001)$, which remained significant after multivariate adjustment for age, height, body mass and BSA (table 3 ).

\section{Common ECG characteristics}

West-Asian athletes demonstrated significantly lower HRs compared with West-Asian controls $(p<0.001)$. Athletes of black and Caucasian origin had significantly lower HRs $(p<0.05)$ than West-Asian athletes (table 4). The PR interval was significantly more prolonged $(p<0.05)$ in black and Caucasian athletes when compared with West-Asian athletes, with no differences observed between black and Caucasian athletes. Black athletes had a significantly greater $(p<0.05)$ frequency of first-degree AV block and early repolarisation than West-Asian and Caucasian athletes. Twenty-three per cent of

Table 2 Demographics of West-Asian, black and Caucasian male athletes

\begin{tabular}{|c|c|c|c|c|}
\hline & West-Asian $(n=800)$ & Black $(n=300)$ & Caucasian $(n=120)$ & West-Asian controls $(n=135)$ \\
\hline Age (years) & $21.4 \pm 6.0^{* \dagger}[12-35]$ & $23.7 \pm 5.0[12-35]$ & $26.6 \pm 4.5^{\ddagger}[17-35]$ & $22.6 \pm 6.0[12-35]$ \\
\hline Height (cm) & $172.7 \pm 11^{\dagger}[122-205]$ & $181 \pm 13.6[115-217]$ & $188.1 \pm 12^{\ddagger}[159-214]$ & $169.9 \pm 10[128-192]$ \\
\hline Body mass (kg) & $69 \pm 16.5^{\dagger}[22-150]$ & $79.3 \pm 17.7[28-156]$ & $86.7 \pm 14.3^{\ddagger}[58-122]$ & $70.3 \pm 19.4[26-154]$ \\
\hline $\mathrm{BSA}\left(\mathrm{m}^{2}\right)$ & $1.74 \pm 0.43^{\dagger \S}[0.87-2.64]$ & $1.91 \pm 0.48[0.92-3.04]$ & $2.1 \pm 0.36^{\ddagger}[1.60-2.63]$ & $1.68 \pm 0.52[1.15-2.71]$ \\
\hline
\end{tabular}

Values are expressed as mean $\pm \mathrm{SD}$ and [range].

*West-Asian athletes vs West-Asian controls, $p<0.05$.

${ }^{\dagger}$ West-Asian athletes vs black and Caucasian athletes, $\mathrm{p}<0.001$

${ }^{\ddagger}$ West-Asian and black athletes vs Caucasian athletes, $\mathrm{p}<0.05$.

${ }^{\S}$ West-Asian athletes vs black athletes, $\mathrm{p}<0.05$.

Table 3 Common and uncommon ECG traits according to the ESC 2010 position statement, ${ }^{8}$ together with multivariate predictors of uncommon ECG findings in West-Asian, black and Caucasian male athletes

\begin{tabular}{|c|c|c|c|c|}
\hline & West-Asian $(n=800)$ & Black $(n=300)$ & Caucasian $(n=120)$ & West-Asian controls $(n=135)$ \\
\hline Common and training-related ECG changes & $723(90.4 \%)^{*}$ & $279(94.6 \%)^{\dagger}$ & $117(97.6 \%)^{\ddagger}$ & $105(77.8 \%)$ \\
\hline \multirow[t]{3}{*}{ Uncommon and training-unrelated ECG changes } & $63(7.9 \%)^{*}$ & $53(18 \%)^{\S}$ & $5(5.8 \%)$ & $0(0 \%)$ \\
\hline & \multicolumn{2}{|l|}{ Univariate } & \multicolumn{2}{|l|}{ Multivariate $^{\pi}$} \\
\hline & RR $(95 \% \mathrm{CI})$ & p Value & $\mathbf{R R}(95 \% \mathrm{CI})$ & p Value \\
\hline Black vs West-Asian & 2.56 (1.73 to 3.98$)$ & $<0.001$ & 2.65 (1.69 to 4.16$)$ & $<0.001$ \\
\hline Black vs Caucasian & 3.54 (1.56 to 8.02$)$ & 0.001 & $3.1(1.34$ to 7.16$)$ & 0.008 \\
\hline West-Asian vs Caucasian & $0.73(0.32$ to 1.62$)$ & 0.432 & $0.86(0.36$ to 2.03$)$ & 0.856 \\
\hline
\end{tabular}

Values are expressed frequency and (\%).

*West-Asian athletes vs West-Asian controls, $\mathrm{p}<0.05$.

${ }^{\dagger}$ Black athletes vs West-Asian athletes, $\mathrm{p}<0.05$.

${ }^{\ddagger}$ Caucasian athletes vs West-Asian athletes, $\mathrm{p}<0.05$.

§Black athletes vs West-Asian and Caucasian athletes, $\mathrm{p}<0.05$.

"Adjusted for age, height, body mass and body surface area.

Table 4 Comparison of common electrocardiographic characteristics between West-Asian, black and Caucasian male athletes

\begin{tabular}{lllll}
\hline & West-Asian $(\mathbf{n = 8 0 0})$ & Black $(\mathbf{n = 3 0 0})$ & Caucasian (n=120) & West-Asian controls (n=135) \\
\hline Resting HR (bpm) & $58.9 \pm 11.3^{*}[28-98]$, & $53.8 \pm 9.9^{\dagger}[34-88]$, & $52 \pm 8.5^{\ddagger}[36-80]$, & $63.2 \pm 11.4[39-94]$, \\
$(\mathrm{n} \leq 60, \%)$ & $493(62 \%)$ & $239(80 \%)$ & $99(83 \%)$ & $66(49 \%)$ \\
PR interval (ms) & $160.3 \pm 29.5[80-300]$, & $176.9 \pm 33.2^{\dagger}[90-360]$, & $168.8 \pm 35.7^{\ddagger}[100-340]$, & $158 \pm 26.1[114-200]$, \\
$(\mathrm{n} \geq 200, \%)$ & $36(4.5 \%)$ & $39(13 \%)$ & $5(4.2 \%)$ & $3(2.2 \%)$ \\
ORS duration (ms) & $86.9 \pm 9.1[66-120]$, & $86.9 \pm 9.9[68-124]$, & $91.6 \pm 11[74-116]$, & $85.8 \pm 8.9[68-126]$, \\
$(\mathrm{n} \geq 120, \%)$ & $3(0.4 \%)$ & $5(1.7 \%)$ & $0(0 \%)$ & $1(0.7 \%)$ \\
OTc interval (ms) & $396 \pm 26.4[305-500]$, & $391.5 \pm 25.9[330-470]$, & $398.2 \pm 34.3[360-460]$, & $389.5 \pm 24.7[340-450]$, \\
(n $\geq 470, \%)$ & $4(0.5 \%)$ & $1(0.3 \%)$ & $0(0 \%)$ & $0(0 \%)$ \\
First-degree AV block & $36(4.5 \%)$ & $39(13.2 \%)^{\S}$ & $5(4.2 \%)$ & $3(2.2 \%)$ \\
Early repolarisation & $477(59.6 \%)^{*}$ & $233(79 \%)^{\S}$ & $80(66.7 \%)$ & $61(45.2 \%)$ \\
IRBBB & $334(41.8 \%)$ & $134(45.4 \%)$ & $72(60 \%)$ & $56(41.5 \%)$ \\
Sokolow-Lyon voltage & $188(23.5 \%)^{*}$ & $79(26.8 \%)$ & $28(23.3 \%)$ & $13(9.6 \%)$ \\
Romhilt-Estes Score & $122(15.3 \%)^{*}$ & $75(25.4 \%)^{\dagger}$ & $23(19.2 \%)$ & $2(1.5 \%)$ \\
\hline
\end{tabular}

Values are expressed as mean $\pm \mathrm{SD}$ and [range], and/or frequency and (\%).

*West-Asian athletes vs West-Asian controls, $p<0.05$.

${ }^{\dagger}$ Black athletes vs West-Asian athletes, $\mathrm{p}<0.05$.

${ }^{\ddagger}$ Caucasian athletes vs West-Asian athletes, $p<0.05$.

${ }^{\S}$ Black athletes vs West-Asian and Caucasian athletes, $\mathrm{p}<0.05$.

$\mathrm{AV}$, arterioventricular; $\mathrm{HR}$, heart rate; IRBBB, incomplete right bundle branch block. 
West-Asian athletes demonstrated significant ECG criteria for LVH compared with $9 \%$ of West-Asian controls $(\mathrm{p}<0.05)$. In athletes, using Sokolow-Lyon voltage criteria, there was no significant difference for the presence of LVH between ethnicity. By contrast, using Romhilt-Estes probable score $\geq 4$, the prevalence of LVH in black athletes was significantly greater $(p<0.05)$ than in West-Asian and Caucasian athletes.

\section{Uncommon ECG characteristics}

Black athletes had a significantly greater $(p<0.05)$ frequency of right atrial enlargement, and a significantly greater $(\mathrm{p}<0.05)$ prevalence of anterior $(n=29,9.8 \%)$ and lateral T-wave inversions $(n=18,6.1 \%)$ than both West-Asian and Caucasian athletes (table 5).

\section{Preparticipation screening statistics}

Of the 1220 athletes and 135 West-Asian controls screened, a total of $252(20.7 \%)$ athletes (141 West-Asian athletes (17.6\%), 96 black athletes (32\%), 12 Caucasian athletes (10\%) and $3(2.2 \%)$ West-Asian controls) required echocardiography or additional investigations because of (1) an abnormal ECG $(\mathrm{n}=110),(2)$ a positive questionnaire or physical examination $(\mathrm{n}=99)$ and (3) an abnormal ECG and a positive questionnaire or physical examination $(n=11)$. Ten athletes (5 black, 4 West-Asian and 1 Caucasian) presented with hypertension, 7 of whom demonstrated LVH on echocardiographic examination. All 10 athletes were provided with lifestyle education, and the 6 with the most severe hypertension were started on a pharmacological intervention. None of the 10 athletes were disqualified from sport, after normalisation of their blood pressure. Twelve asymptomatic athletes (1\%; 4 West-Asian and 8 black) showed ST segment elevation with an upward convexity followed by negative $\mathrm{T}$ waves in V2-V4. Fourteen asymptomatic athletes (1.2\%; 4 West-Asian and 10 black) demonstrated deep T-wave inversions in anterior and lateral leads. Of these, six had LVH with a dilated LV, with the remaining eight athletes having deep $\mathrm{T}$-wave inversions in the absence of LVH. A further four asymptomatic athletes $(0.3 \%$; 1 West Asian and 3 black) had deep T-wave inversions in anterior and lateral leads together with a significant FH of SCD in a first-degree relative. After extensive cardiovascular investigation involving CMR and/or genotyping, all four athletes demonstrated no evidence of cardiomyopathy per se, no 'classic' features of dilated cardiomyopathy, arrhythmogenic right ventricular cardiomyopathy (ARVC) or HCM. In conclusion, all 40 athletes were given medical clearance but were required to undergo yearly evaluation and advised to seek immediate medical attention upon becoming symptomatic.

Finally, 7 (0.6\%) athletes (4 West-Asian and 3 black; table 6) were identified with a disease associated with SCD (2 cases of Wolff-Parkinson-White (WPW) syndrome, 1 case of ARVC, 1 long QT syndrome and 3 cases of HCM). The prevalence of a cardiac disease in black athletes was twice that of WestAsian athletes ( $1 \%$ vs $0.5 \%$ ), with no cases observed in this cohort of Caucasian athletes and West-Asian controls. In accordance with risk stratification protocols, these seven athletes were disqualified from competitive sport (note: one athlete with WPW was successfully ablated and returned to full competition 2 months post-ablation). Four athletes had cardiac diagnoses other than inherited disease, including mitral valve prolapse $(n=2)$, interventricular septal defect $(n=1)$ and resting complex ventricular arrhythmia of unknown origin $(n=1)$. Consequently, when accounting for a screening protocol using history, physical examination and 12-lead ECG, high levels of false positives were observed in black (31\%) and West-Asian $(17 \%)$ athletes.

\section{DISCUSSION}

Uncommon ECG changes raising the suspicion of structural heart disease were reported in $10 \%$ of all athletes. Black ethnicity was positively associated with frequencies of uncommon ECG findings, with black African descent being an independent predictor of uncommon ECG findings when compared with West-Asian (2.6:1) and Caucasian athletes (3.5:1). Seven athletes were identified with a disease associated with SCD, with prevalence being two times higher in black athletes compared with West-Asian athletes ( $1 \%$ vs $0.5 \%$ ).

The prevalence of common ECG modifications was comparable between West-Asian and Caucasian athletic populations, whereas black athletes demonstrated a significantly greater frequency of right atrial enlargement, first-degree AV block and early repolarisation. Similar to Caucasian athletes, ${ }^{1}$ West-Asian athletes demonstrated a significantly greater magnitude of Sokolow voltage criteria for LVH compared with West-Asian controls $(23.5 \%$ vs $9.6 \%$, p<0.05), but with no significant differences in LVH between ethnicity of the athletes.

Table 5 Comparison of uncommon electrocardiographic characteristics between West-Asian, black and Caucasian male athletes

\begin{tabular}{|c|c|c|c|c|}
\hline & $\begin{array}{l}\text { West-Asian } \\
(n=800)\end{array}$ & $\begin{array}{l}\text { Black } \\
(n=300)\end{array}$ & $\begin{array}{l}\text { Caucasian } \\
(n=120)\end{array}$ & $\begin{array}{l}\text { West-Asian } \\
\text { controls }(n=135)\end{array}$ \\
\hline RA enlargement & $12(1.5 \%)$ & $14(4.7 \%)^{*}$ & $0(0 \%)$ & $1(1 \%)$ \\
\hline LA enlargement & $9(1.1 \%)$ & $6(2 \%)$ & $1(0.8 \%)$ & $0(0 \%)$ \\
\hline RAD & $9(1.1 \%)$ & $5(1.7 \%)$ & $2(1.7 \%)$ & $0(0 \%)$ \\
\hline LAD & $6(0.8 \%)$ & $2(0.7 \%)$ & $3(2.5 \%)$ & $0(0 \%)$ \\
\hline ST segment depression & $2(0.3 \%)$ & $2(0.7 \%)$ & $0(0 \%)$ & $0(0 \%)$ \\
\hline 0 waves & $3(0.4 \%)$ & $0(0 \%)$ & $0(0 \%)$ & $3(0.2 \%)$ \\
\hline CRBBB & $1(0.1 \%)$ & $1(0.3 \%)$ & $0(0 \%)$ & $0(0 \%)$ \\
\hline ILBBB & $3(0.4 \%)$ & $3(1.0 \%)$ & $1(0.8 \%)$ & $0(0 \%)$ \\
\hline Anterior T-wave inversion & $23(2.9 \%)$ & $29(9.8 \%)^{*}$ & $0(0 \%)$ & $0(0 \%)$ \\
\hline Lateral T-wave inversion & $13(1.6 \%)$ & $18(6.1 \%)^{*}$ & $0(0 \%)$ & $0(0 \%)$ \\
\hline RVH & $8(1.0 \%)$ & $1(0.3 \%)$ & $0(0 \%)$ & $0(0 \%)$ \\
\hline
\end{tabular}

*Black athletes vs West-Asian and Caucasian athletes; $\mathrm{p}<0.05$, Values are expressed as frequency and (\%). CRBBB, complete right bundle branch block; HR, heart rate; ILBBB, incomplete left bundle branch block; LA, left atrial; $L A D$, left axis deviation; $R A$, right atrial; $R A D$, right axis deviation; $R V H$, right ventricular hypertrophy. 


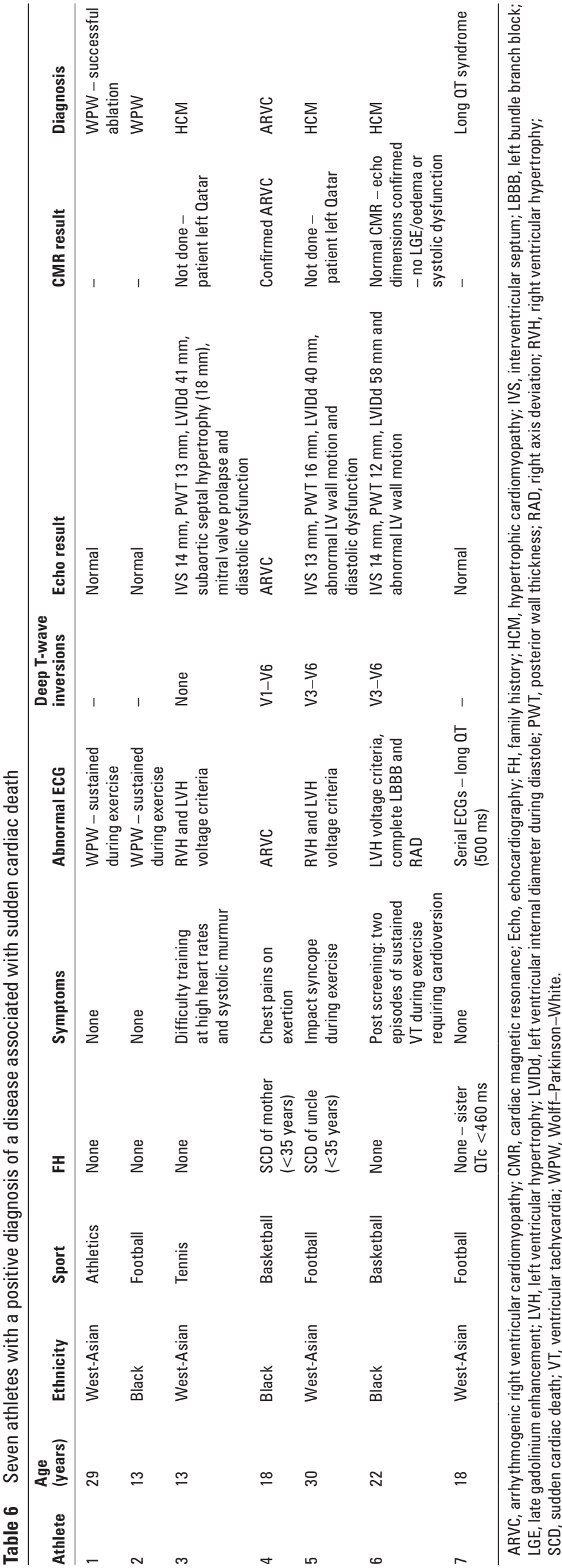

By comparison, using Romhilt-Estes score of $\geq 4$, the prevalence of LVH in black athletes was significantly greater $(p<0.05)$ than in both West-Asian and Caucasian athletes. Recent evidence suggests a racial predilection for black athletes to develop LVH in response to the exercise, possibly as a result of a combination of genetic, endocrine and haemodynamic factors. ${ }^{5}$ In the present study, FH of hypertension and basal blood pressure did not differ with ethnicity, although 10 athletes demonstrated significant hypertension and 7 athletes displayed concentric LVH (average $15 \mathrm{~mm}$ ), with 6 warranting pharmacological intervention.

\section{Repolarisation: physiological or pathological?}

Early repolarisation has traditionally been viewed as a benign ECG phenomenon. ${ }^{8}$ The present study observed an elevated ST segment with an upward convexity, followed by $\mathrm{T}$-wave inversion usually in leads V2-V4, in four West-Asian and eight black athletes. Care is required as this ECG abnormality with the 'domed' morphology of the elevated ST segment needs to be differentiated from the Brugada syndrome. Following extensive further examination, the present data confirm this early repolarisation morphology in West-Asian and black athletes to be physiological, not requiring future investigation. By contrast, deep T-wave inversions in the lateral leads are of a major concern, as these ECG alterations are a recognised manifestation of HCM and ARVC. Black athletes presented with a significantly higher prevalence of anterior $(9.8 \%, p<0.001)$ and lateral $(6.1 \%, p=0.005)$ deep T-wave inversions when compared with West-Asian and Caucasian athletes.

Together with seven athletes identified as having a disease associated with SCD, the present study encountered two complex screening scenarios: First, 14 asymptomatic athletes (1.2\%; 4 West-Asian and 10 black) demonstrated deep T-wave inversions in anterior and lateral leads. Of these, six had LVH with a dilated LV, with the remaining eight athletes having deep T-wave inversions in the absence of LVH. Second, a group of four asymptomatic athletes $(0.3 \%$; 1 West Asian and 3 black) displayed deep $\mathrm{T}$-wave inversions in anterior and lateral leads, together with a significant FH of SCD in a first-degree relative. None of the 18 athletes exhibited a non-dilated LV cavity, ${ }^{12}$ enlarged left atrium $>50 \mathrm{~mm},{ }^{13} \mathrm{LV}$ obstruction ${ }^{14}$ or evidence of impaired myocardial relaxation ${ }^{15}$ suggestive of HCM. Upright exercise testing and 24-h ECG failed to identify abnormalities in blood pressure responses ${ }^{16}$ or non-sustained ventricular tachycardia. ${ }^{17}$ Following CMR imaging and/or genotyping, the authors failed to identify apical HCM, pathological hypertrophy of the anterolateral wall, myocardial fibrosis or characteristic right ventricular morphology-associated ARVC in any athlete. In conclusion, all 18 athletes demonstrated no evidence of cardiomyopathy per se, and no 'classic' features of dilated cardiomyopathy, ARVC or HCM.

The diagnostic uncertainty in these two groups of athletes requires careful consideration, as the $\mathrm{FH}$ of SCD in the latter group of a cohort of four athletes is striking. Pelliccia et a ${ }^{18}$ reported on 81 athletes with deeply inverted $T$ waves with no apparent cardiac disease, who had undergone serial clinical, ECG and echocardiographic studies for $9 \pm 7$ years (range 1-27). Of 81 athletes identified, $5(6 \%)$ ultimately proved to have cardiomyopathies. The authors suggest that these abnormal ECGs may represent the initial expression of genetic cardiac disease that may not be evident for many years. As a result, the clinical significance of deep $\mathrm{T}$-wave inversions in West-Asian 
and black athletes remains to be determined, and the ECG findings in these two groups of athletes are currently classed as neither physiological nor pathological. In the absence of obvious pathology, FH of SCD and/or serious personal symptoms, deep T-wave inversions in some West-Asian and black athletes may represent a normal spectrum of ECG changes in response to physical training.

The $0.5 \%$ prevalence of a diagnosed SCD disease in WestAsian athletes is consistent with that reported by previous studies in Caucasian athletes ${ }^{3}$ and should be considered acceptable for establishing a population-based screening programme. However, the $1 \%$ prevalence of a diagnosed SCD disease in the black athletes is three times greater than that observed in previous studies among Caucasian athletes, estimated approximately at $0.3 \%$. This observation suggests that preparticipation ECG screening in black athletes could be considered favourable, despite the rate of false positives (31\%) using history, physical examination and 12-lead ECG, about three times greater than Caucasian athletes $(10 \%),{ }^{3}$ given the rapidly growing understanding of the ECGs of black Africans. Overall, 270 athletes $(22 \%)$ had at least one finding on history and physical examination that warranted further cardiovascular consultation, of which $252(20.7 \%)$ athletes underwent echocardiography or additional investigations. This false-positive rate is important as no athlete was identified with an inherited cardiac disease on the basis of history and physical examination alone. Importantly, despite large variance in the ECG false-positive rate between ethnicities, in this study, 12-lead ECG-driven screening produced a $50 \%$ lower global total false-positive rate (121 athletes; $9.9 \%$ ) than history and physical examination. Future research should look to examine the cost-benefit ratio, together with the sensitivity/specificity of resting 12-lead ECG screening in large ethnically diverse athletic and non-athletic populations.

\section{Limitations}

Without long-term outcome data on the 18 athletes demonstrating deep T-wave inversions with/without a positive $\mathrm{FH}$ of SCD, the precise significance of such repolarisation changes remains unresolved. Furthermore, there is no 'gold standard' test for the diagnosis of the presence or absence of heart diseases in these athletes. Although genetic testing is the most specific method of diagnosing HCM, the diverse genetic heterogeneity of HCM and incomplete knowledge of all causal mutations lend poor sensitivity to this diagnostic tool.

\section{CONCLUSION}

Only black ethnicity was an independent predictor of 'uncommon' ECG traits, with West-Asian and Caucasian athletes demonstrating comparable rates of common and uncommon ECG modifications. Seven athletes were identified with a disease associated with SCD, with prevalence being two times higher in black athletes compared with West-Asian athletes. In conclusion, a physiological versus pathological conundrum was documented in 18 athletes with repolarisation abnormalities suggestive of cardiomyopathy, ultimately reflecting the unresolved understanding of marked repolarisation abnormalities and inherited pathology. Future work should examine the genetic mechanisms behind electrocardiographic and myocardial adaptations in athletes of diverse ethnicity. This will aid in the clinical differentiation between physiological remodelling and potential cardiomyopathy or ion channel disorder.

\section{What is already known on this topic}

- Athletes' ethnicity may have an impact on both their cardiovascular response to exercise and risk of sudden cardiac death.

- There is no data on electrocardiographic modifications for West-Asian athletes, increasing the risk of false-positive diagnoses and unnecessary disqualification for this Middle-Eastern and Gulf population.

\section{What this study adds}

- West-Asian and Caucasian athletes demonstrate comparable rates of electrocardiographic (ECG) findings.

- Black African descent is an independent predictor of 'uncommon' ECG changes when compared with West-Asian and Caucasian athletes.

- The prevalence of a disease associated with sudden cardiac death was two times higher in black athletes than in West-Asian athletes.

\section{Competing interests None.}

Patient consent Obtained.

Ethics approval This study was conducted with the approval of the Qatar Orthopaedic and Sports Medicine Hospital ethics committee.

Provenance and peer review Not commissioned; externally peer reviewed.

\section{REFERENCES}

1. Sharma S, Whyte G, Elliott P, et al. Electrocardiographic changes in 1000 highly trained junior elite athletes. Br J Sports Med 1999;33:319-24.

2. Corrado D, Basso C, Thiene G. Essay: sudden death in young athletes. Lancet 2005;366(Suppl 1):S47-8.

3. Wilson MG, Basavarajaiah S, Whyte GP, et al. Efficacy of personal symptom and family history questionnaires when screening for inherited cardiac pathologies: the role of electrocardiography. Br J Sports Med 2008;42:207-11.

4. Maron BJ, Carney KP, Lever HM, et al. Relationship of race to sudden cardiac death in competitive athletes with hypertrophic cardiomyopathy. J Am Coll Cardiol 2003;41:974-80.

5. Basavarajaiah S, Boraita A, Whyte G, et al. Ethnic differences in left ventricular remodeling in highly-trained athletes relevance to differentiating physiologic left ventricular hypertrophy from hypertrophic cardiomyopathy. J Am Coll Cardiol 2008;51:2256-62.

6. Rawlins J, Carre F, Kervio G, et al. Ethnic differences in physiological cardiac adaptation to intense physical exercise in highly trained female athletes. Circulation 2010;121:1078-85.

7. Magalski A, Maron BJ, Main ML, et al. Relation of race to electrocardiographic patterns in elite American football players. J Am Coll Cardiol 2008;51:2250-5.

8. Corrado D, Pelliccia A, Heidbuchel $\mathrm{H}$, et al. Recommendations for interpretation of 12-lead electrocardiogram in the athlete. Eur Heart J 2010;31:243-59.

9. Corrado D, Pelliccia A, Bjørnstad HH, et al. Cardiovascular pre-participation screening of young competitive athletes for prevention of sudden death: proposal for a common European protocol. Consensus Statement of the Study Group of Sport Cardiology of the Working Group of Cardiac Rehabilitation and Exercise Physiology and the Working Group of Myocardial and Pericardial Diseases of the European Society of Cardiology. Eur Heart J 2005;26:516-24.

10. Zipes DP, Ackerman MJ, Estes NA, 3rd, et al. Task Force 7: arrhythmias. J Am Coll Cardiol 2005;45:1354-63.

11. Basavarajaiah S, Wilson M, Junagde S, et al. Physiological left ventricular hypertrophy or hypertrophic cardiomyopathy in an elite adolescent athlete: role of detraining in resolving the clinical dilemma. Br J Sports Med 2006;40:727-9; discussion 729 .

12. Maron BJ, Pelliccia A, Spirito P. Cardiac disease in young trained athletes. Insights into methods for distinguishing athlete's heart from structural heart disease, with particular emphasis on hypertrophic cardiomyopathy. Circulation 1995;91:1596-601. 
13. Pelliccia A, Maron BJ, Di Paolo FM, et al. Prevalence and clinical significance of left atrial remodeling in competitive athletes. J Am Coll Cardiol 2005;46:690-6.

14. Lewis JF, Spirito P, Pelliccia A, et al. Usefulness of Doppler echocardiographic assessment of diastolic filling in distinguishing "athlete's heart" from hypertrophic cardiomyopathy. Br Heart J 1992;68:296-300.

15. Cardim N, Oliveira AG, Longo S, et al. Doppler tissue imaging: regional myocardial function in hypertrophic cardiomyopathy and in athlete's heart. J Am Soc Echocardiogr 2003;16:223-32.
16. Barley J, Blackwood A, Miller M, et al. Angiotensin converting enzyme gene I/D polymorphism, blood pressure and the renin-angiotensin system in Caucasian and Afro-Caribbean peoples. J Hum Hypertens 1996;10:31-5.

17. Monserrat L, Elliott PM, Gimeno JR, et al. Non-sustained ventricular tachycardia in hypertrophic cardiomyopathy: an independent marker of sudden death risk in young patients. J Am Coll Cardiol 2003:42:873-9.

18. Pelliccia A, Di Paolo FM, Quattrini FM, et al. Outcomes in athletes with marked ECG repolarization abnormalities. N Engl J Med 2008;358:152-61. 